\title{
The nail dystrophy of psoriatic arthritis
}

\author{
C. J. EASTMOND, AND V. WRIGHT
}

From the Departments of Rheumatology, General Infirmary, Leeds, and Royal Bath Hospital, Harrogates and the Rheumatism Research Unit, University of Leeds

SUMMARY Nail abnormalities occur frequently in patients with psoriatic arthritis. This study of the finger nails of 46 patients with psoriatic arthritis, 100 nonpsoriatic rheumatism patients, and $10 \%$ nonpsoriatic general medical patients was designed to characterise these abnormalities with partiw cular reference to the severity of nail pitting. The results of the study suggest: (1) Onycholysis alone in the absence of previous injury to the affected nail is in favour of a psoriatic origin for the naip dystrophy. (2) Two or all of onycholysis, horizontal ridging, and nail pitting in the same patient are in favour of a psoriatic origin for the nail dystrophy. (3) The presence or absence of nail pitting alone is a poor discriminator between psoriatic and other causes for nail dystrophy. (4) More than $2 \overrightarrow{0}$ finger nail pits per person is suggestive of a psoriatic cause for the dystrophy. (5) More than 60 pit per person is unlikely to be found in the absence of psoriasis.

It is well recognised that abnormalities of the nails occur in psoriasis (Samman, 1972). Patients with psoriatic arthritis have a nail dystrophy more frequently than those with uncomplicated psoriasis. The frequency of this dystrophy has been noted to be as high as $80 \%$ in patients with psoriatic arthritis (Wright, 1959: Baker et al., 1964). The presence of abnormalities of the nails may be of diagnostic help in patients with an inflammatory arthritis, especially when there is no psoriasis of the skin, and also in family studies. Since similar abnormalities may occur from causes other than psoriasis (Samman, 1972) it is important to know which abnormalities might be considered as evidence for psoriasis when the skin features are minimal or totally absent. This study was designed to characterise these abnormalities.

\section{Materials and methods}

The patients studied included 46 patients with psoriatic arthritis (Moll and Wright, 1973), 100 patients with other rheumatological conditions, and 100 patients recently admitted to hospital with nonrheumatological conditions. The finger and thumb nails were examined by naked eye without magnification in a good light, and the presence of nail pits, onycholysis, and palpable ridging of the nails

Accepted for publication 25 May 1978

Correspondence to Dr C. J. Eastmond, Rheumatism Research Unit, School of Medicine, University of Leeds, 36 Clarendon Road, Leeds LS2 9PJ was noted for each nail. The number of pits visible in each nail also was recorded. The patients werE asked if their employment or hobbies involve regular trauma to the nails, and this was estimate as being mild, moderate, or severe. Nail biting wa@ considered to be mild regular trauma. Sever $\overrightarrow{\bar{E}}$ regular trauma was considered to be present whe the individuals regularly used heavy tools likely to damage the nail. Each patient was also asked severe injury or infection had previously damage a nail, and this was recorded. Inquiry was made fof a family history of psoriasis.

\section{Results}

The mean age and sex distribution of the patients in each of the 3 groups is given in Table 1 . The non psoriatic rheumatic patients had a higher proportion of females than the other 2 groups, but this was nof statistically significant. The mean age of the general medical patients was higher than in the other groups $(\mathrm{P}<0 \cdot 01)$.

Table 1 Mean ages ( $\pm 1 S E$ ) and sex distribution of the patients with regard to diagnostic group

\begin{tabular}{|c|c|c|c|}
\hline $\begin{array}{l}\text { Diagnostic } \\
\text { group }\end{array}$ & $\begin{array}{l}\text { Psoriatic } \\
\text { arthritis } \\
n=46\end{array}$ & $\begin{array}{l}\text { Nonpsoriatic } \\
\text { rheumatic } \\
\text { patients } \\
n=100\end{array}$ & $\begin{array}{l}\text { Nonpsoriatic } \\
\text { general } \\
\text { medical } \\
\text { patients } \\
n=100\end{array}$ \\
\hline $\begin{array}{l}\text { Mean age } \\
\pm 1 \text { SE (yr) } \\
\text { Male: female ratio }\end{array}$ & $\begin{array}{l}50 \cdot 4 \\
\pm 2 \cdot 0 \\
0 \cdot 77\end{array}$ & $\begin{array}{l}54 \cdot 6 \\
\pm 1 \cdot 5 \\
0 \cdot 56\end{array}$ & $\begin{array}{l}62 \cdot 0 \\
\pm 1 \cdot 8 \\
0 \cdot 85\end{array}$ \\
\hline
\end{tabular}


Table 2 Percentage frequencies of onycholysis, nail pitting, and horizontal ridging, alone and in combinations, in the finger nails

\begin{tabular}{|c|c|c|c|}
\hline \multirow[t]{2}{*}{ Nail abnormality } & \multicolumn{3}{|c|}{ Patient with } \\
\hline & $\begin{array}{l}\text { Psoriatic } \\
\text { arthritis } \\
n=46\end{array}$ & $\begin{array}{l}\text { Nonpsoriatic } \\
\text { rheumatic } \\
\text { patients } \\
n=100\end{array}$ & $\begin{array}{l}\text { Nonpsoriatic } \\
\text { general medical } \\
\text { patients } \\
n=100\end{array}$ \\
\hline Normal & $15 \cdot 2$ & $52 \cdot 0$ & $49 \cdot 0$ \\
\hline Onycholysis alone & $4 \cdot 3$ & 0.0 & $2 \cdot 0^{*}$ \\
\hline $\begin{array}{l}\text { Horizontal } \\
\text { ridging alone }\end{array}$ & $4 \cdot 3$ & $8 \cdot 0$ & $4 \cdot 0$ \\
\hline Pitting alone & $23 \cdot 9$ & $40 \cdot 0$ & $41 \cdot 0$ \\
\hline $\begin{array}{l}\text { Onycholysis and } \\
\text { pitting }\end{array}$ & $23 \cdot 9 * *$ & 0.0 & $4 \cdot 0^{*}$ \\
\hline Onycholysis and & & & \\
\hline $\begin{array}{l}\text { horizontal ridging } \\
\text { Horizontal ridging }\end{array}$ & $2 \cdot 2$ & 0.0 & 0.0 \\
\hline $\begin{array}{l}\text { Horizontal ridging } \\
\text { and pitting } \\
\text { Onycholysis, horizontal }\end{array}$ & $13 \cdot 0$ & 0.0 & 0.0 \\
\hline ridging and pitting & $13 \cdot 0$ & 0.0 & 0.0 \\
\hline
\end{tabular}

*History of injury to the affected nail in all patients.

**History of injury to 1 of 4 affected nails in 1 patient.

Table 2 shows the frequencies of the 3 abnormalities studied (onycholysis, horizontal ridging, and pitting). Overall, $84.8 \%$ of patients with psoriatic arthritis had abnormalities of the nails compared with $48 \%$ and $51 \%$ of the nonpsoriatic rheumatic patients and general medical patients respectively. Onycholysis without a history of previous injury to the affected nail occurred only in patients with psoriatic arthritis. Horizontal ridging alone was equally common in all 3 groups of patients. Pitting alone occurred more frequently in nonpsoriatic rheumatic patients $(40.0 \%)$ and general medical patients $(41.0 \%)$ than in patients with psoriatic arthritis $(23.9 \%)$. Combinations of 2 or more of these 3 abnormalities without a history of previous injury to the affected nail occurred only in patients with psoriatic arthritis. There were no differences in the frequencies of individual abnormalities between the 2 groups who did not have psoriasis except for the absence of onycholysis in the rheumatic patients.

Eleven patients with psoriatic arthritis, 40 nonpsoriatic rheumatic patients, and $\mathbf{4 1}$ general medical patients had nail pits alone. Patients with psoriatic arthritis had more pits than patients in the other 2 groups (Table 3 ). Three $(27 \cdot 3 \%)$ of the eleven patients with psoriatic arthritis had more than a total of 20 pits compared with $7 \cdot 5 \%$ of the 40 nonpsoriatic rheumatic patients and $4.9 \%$ of the 41 general medical patients $(0 \cdot 1>P>0 \cdot 05)$. All three $(27 \cdot 3 \%)$ patients with more than 20 nail pits had more than 60 nail pits, whereas patients without psoriatic arthritis were not found with more than 60 nail pits $(\mathrm{P}<0.001)$. In patients with psoriatic arthritis who had other finger nail abnormalities in association with pitting the proportion of patients
Table 3 Percentage of patients with nail pitting alone with different degrees of nail pitting

\begin{tabular}{llll}
\hline $\begin{array}{l}\text { Number of nail } \\
\text { pits per person }\end{array}$ & \multicolumn{3}{l}{ Patients with } \\
\cline { 2 - 4 } & $\begin{array}{l}\text { Psoriatic } \\
\text { arthritis } \\
n=11\end{array}$ & $\begin{array}{l}\text { Nonpsoriatic } \\
\text { rheumatic } \\
\text { patients } \\
n=40\end{array}$ & $\begin{array}{l}\text { Nonpsoriatic } \\
\text { general medical } \\
\text { patients } \\
n=40\end{array}$ \\
\hline 20 nail pits & 27.3 & 7.5 & 4.9 \\
$>60$ nail pits & 27.3 & 0.0 & 0.0 \\
\hline
\end{tabular}

Table 4 Percentage of patients with psoriatic arthritis and nail pitting alone and in association with other abnormalities with different degrees of nail pitting

\begin{tabular}{lll}
\hline $\begin{array}{l}\text { Number of nail } \\
\text { pits per person }\end{array}$ & $\begin{array}{l}\text { Nail pitting } \\
\text { alone } \\
n=11\end{array}$ & $\begin{array}{l}\text { Nail pitting and } \\
\text { other abnormalities } \\
n=23\end{array}$ \\
\hline$>20$ nail pits & $27 \cdot 3$ & $69 \cdot 6$ \\
$>60$ nail pits & $27 \cdot 3$ & $65 \cdot 6$ \\
\hline
\end{tabular}

with more than 20 pits $(69.6 \%)$ was higher than when pitting was the only abnormality (Table 4). All but one of these patients had more than 60 nail pits.

Longitudinal ridging of 1 or more nails occurred with equal frequency in all 3 clinical groups: in $71.7 \%$ of patients with psoriatic arthritis, in $77 \%$ of rheumatic patients without psoriasis, and in $80 \%$ of general medical patients. In all 3 groups this abnormality was related to age, being more frequent in older patients.

\section{Discussion}

Robertson and Braune (1974) studied the nails of 64 hospital staff and found nail pitting in $58 \%$. Only 1 person had more than 20 nail pits. They found onycholysis in 1 nail and simple transverse grooving in $25 \%$ of subjects. We have found a slightly lower prevalence of pits in nonpsoriatic patients, and this could be accounted for by the fact that the previous workers examined the nails with magnification whereas we did not. We considered horizontal ridging to be present only when it was palpable, and this may account for only $6 \%$ of our nonpsoriatic patients having this feature compared with $25 \%$ of those of Robertson and Braune (1974) having transverse grooves. In both studies onycholysis was rarely present in the absence of psoriasis without previous injury to the affected nail. In the present study no attempt was made to examine nail clippings for mycelia, but it is possible that such infections could be the cause of onycholysis in some patients' nails. Since such infections are unusual in psoriatic nails (Zaias, 1969) it is possible that examination of 
the nail clippings for mycelia may improve the discriminatory value of onycholysis as a feature of psoriatic nail dystrophy.

The present study shows the necessity for recording the number of nail pits in addition to their presence or absence. Pitting alone occurred more frequently in patients without psoriasis than in patients with psoriatic arthritis, but more than 20 nail pits per person was less common in patients who did not have psoriasis. More than 60 pits did not occur in the absence of psoriasis, whereas $27 \cdot 3 \%$ of patients with psoriatic arthritis and nail pitting alone had more than 60 pits. Similarly, in the total group of patients with psoriatic arthritis and nail pitting the presence of more than 20 nail pits per patient was usually associated with gross pitting. Two or more of the 3 features looked for (onycholysis, palpable horizontal ridging, and nail pitting) were not found in patients without psoriasis in the absence of a history of previous injury to the affected nail. This suggests that where 2 or more of these features occur together in the same patient they are likelstes to be caused by psoriasis.

Longitudinal ridging is recognised to occur in older healthy people (Samman, 1972) and is no? indicative of psoriasis. Our finding of this abnor흘 mality in older patients irrespective of diagnostic group confirms these previous findings.

\section{References}

Baker, H., Golding, D. N., and Thompson, M. (1964). The nails in psoriatic arthritis. British Journal of Dermatology 76, 549-554.

Moll, J. M. H., and Wright, V. (1973). Psoriatic arthritisa Seminars in Arthritis and Rheumatism, 3, 55-78.

Robertson, J. C., and Braune, M. L. (1974). Splinter haemorí rhages, pitting, and other findings in finger nails ofo healthy adults. British Medical Journal, 4, 279-281.

Samman, P. D. (1972). The Nails in Disease, 2nd edñ Heinemann: London.

Wright, V. (1959). Psoriatic arthritis-a comparative studf of rheumatoid arthritis and arthritis associated with. psoriasis. Archives of Dermatology, 80, 27-35.

Zaias, N. (1969). Psoriasis of the nail-a clinico-pathof logical study. Archives of Dermatology, 99, 567-579. 